\title{
Silicon Photodetectors Based on Internal Photoemission Effect: The Challenge of Detecting Near-Infrared Light
}

\author{
Maurizio Casalino, Luigi Sirleto, Mario Iodice and Giuseppe Coppola \\ Istituto per la Microelettronica e Microsistemi, Consiglio Nazionale delle Ricerche, Naples

\section{Introduction}

Silicon Photonics has emerged as an interesting field due to its potential for low-cost optical components integrated with electronic functionality. In the past two decades, there has been growing interest in photonic devices based on Si-compatible materials (Kimerling et al., 2004; Jalali \& Fathpour, 2006) in the field both of the optical telecommunications and of the optical interconnects. In this contest, tremendous progresses in the technological processes based on the use silicon-on insulator (SOI) substrates have allowed to obtain reliable and effectiveness full complementary metal-oxide semiconductor (CMOS) compatible optical components such as, low loss waveguides, high-Q resonators, high speed modulators, couplers, and optically pumped lasers (Rowe et al., 2007 ; Vivien et al., 2006 ; Xu et al., 2007 ; Michael et al., 2007; Liu et al., 2007 ; Liu et al., 2006). All these devices have been developed to operate in the wavelength range from C optical band (1528 - $1561 \mathrm{~nm})$ to L optical band $(1561-1620 \mathrm{~nm})$. However one of the crucial steps toward the integration of photonics with electronics resides in the development of efficient chip-scale photodetectors (PD) integrated on Si. Bulk photodetectors are perhaps the oldest and best understood silicon optoelectronic devices. Commercial products in Si operate at wavelengths below $1100 \mathrm{~nm}$, where band-toband absorption occurs. For the realization of photodiodes integrated in photonics circuits operating at wavelengths beyond $1100 \mathrm{~nm}$ silicon is not the right material because its transparency. In the last years, in order to take advantage of low-cost standard Si-CMOS processing technology, a number of photodetectors have been proposed based on different physical effects, such as: defect-state absorption (Bradley et al., 2005), two photon absorption (TPA) (Liang et al., 2002) and internal photoemission absorption (Zhu et al., 2008a). Physical effects, working principles, main structures reported in literature and the most significant results obtained in recent years were reviewed and discussed in our previous paper (Casalino et al., 2010a). In this paragraph, we go into more depth on photodetectors based on the internal photoemission effect (IPE). Silicon infrared photodiodes based on IPE are not novel, in fact $\mathrm{PtSi} / \mathrm{p}-\mathrm{Si}, \mathrm{Ir} / \mathrm{p}-\mathrm{Si}$ and $\mathrm{Pd}_{2} \mathrm{Si} / \mathrm{p}$-Si junctions are usually used in the infrared imaging systems (Kosonocky et al., 1985). The main advantages of these devices resides in their extremely high switching speed and in their simple fabrication process, but, due to high background current density these devices can only work at cryogenic temperature. 
However, in recent years IPE has emerged as a new option for detecting also near infrared (NIR) wavelengths at room temperature. Unfortunately, the photoemission quantum efficiency is low compared to that of detectors based on inter-band absorption and this limits the application both in power monitoring and in the telecommunication field. Low quantum efficiency is a direct result of conservation of momentum during carrier emission over the potential barrier, in fact, the majority of excited carriers which do not have enough momentum normal to the barrier are reflected and not emitted. Moreover as incoming photons can excite carriers lying in states far below the Fermi energy, which can not overcome over the metal-semiconductor potential barrier, the quantum efficiency of these devices is further decreased. In recent years new approaches and structures are proposed in order to circumvent these limitations.

In this paragraph an overview of the state of the art of NIR all-Si photodetectors based on IPE is presented. First, the physical effects of IPE and the main figures of merit of devices based on IPE are elucidated. Then, the main structures reported in literature, starting from historical devices for imaging application at infrared wavelengths, up to new NIR devices which could be adapted for telecommunications and power monitoring, are described in detail. Finally the most significant results obtained in the last years are reviewed and discussed comparing the performances of devices based on different approaches.

\section{IPE-based device performances}

We hereafter present a theoretical background useful to clarify the physics behind the working principle of devices and we analyze crucial points affecting device performances.

\subsection{Device efficiency and IPE theory}

IPE is the optical excitation of electrons in the metal to energy above the Schottky barrier and then transport of these electrons to the conduction band of the semiconductor. The standard IPE theory is due to Fowler (Fowler, 1931). However, the Fowler's theory was obtained without taking into account the thickness of the Schottky metal layer. In 1973, Archer and Cohen (Archer \& Cohen, 1973) proposed thinning the electrode to increase the emission probability. The enhancement of IPE in thin metal film was theoretically investigated by Vicker who introduce a moltiplicative factor to the Fowler's formula (Vickers, 1971). However the resulting electrode was so thin that it was semitransparent producing low metal absorbance. More recently Casalino et al. proposed to improve the absorbance in NIR photodetector based on IPE by using a microcavity Fabry-Perot (Casalino et al., 2008a, 2010b). Finally a further enhancement of IPE can be obtained due to image force effect which modify the Schottky barrier under a reverse bias favouring IPE. This effect can be taken into account by adding a barrier collection efficiency term. The resulting quantum efficiency of a photodetector based on IPE, can be written by the formula (Casalino et al., 2008b):

$$
\eta=A_{T} F_{e} P_{E} \eta_{c}
$$

where $A_{T}$ is the total optical absorbance of the metal, $F_{e}$ is the Fowler' factor, $P_{E}$ is the Vicker's factor and $\eta_{c}$ is the bias dependent barrier collection efficiency. Very often, device efficiency is described in term of responsivity, a very important property of a detector 
indicating the current produced $\left(\mathrm{I}_{\mathrm{ph}}\right)$ by a certain optical power ( $\left.\mathrm{P}_{\mathrm{OPT}}\right)$. Responsivity is strictly linked to a device's quantum efficiency by the formula:

$$
\Re=\frac{I_{p h}}{P_{O P T}}=\frac{\lambda[n m]}{1242} \eta
$$

Reasonable responsivities are necessary for an acceptable signal-to-noise ratio and to ease the design and realization of the amplifier circuitry that follows.

\subsubsection{Standard fowler's theory of IPE}

IPE is the optical excitation of electrons into the metal to an energy above the Schottky barrier and then transport of these electrons to the conduction band of the semiconductor (Fig. 1).

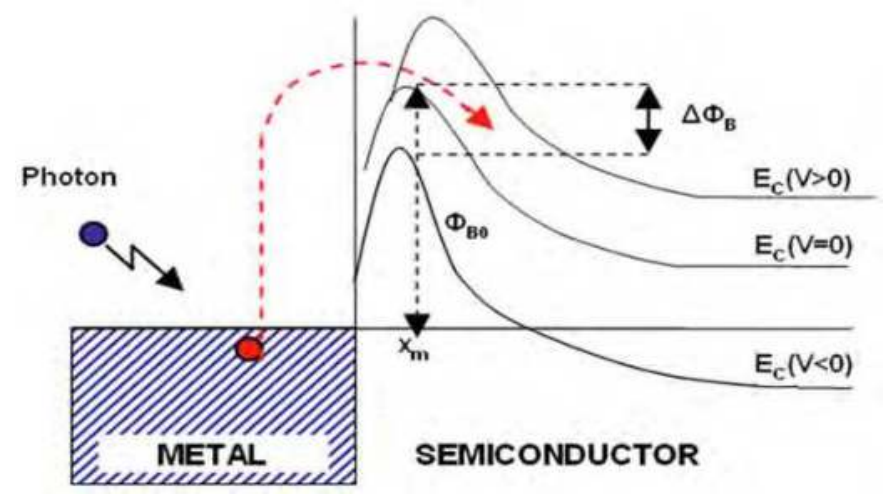

Fig. 1. Energy band diagram for a metal/n-semiconductor junction. "Reprinted with permission from M. Casalino et al., "A silicon compatible resonant cavity enhanced photodetector working at $1.55 \mu \mathrm{m}$," Semicond. Sci. Technol., 23, 075001, 2008 (doi: 10.1088/0268-1242/23/7/075001). IOP Publishing is acknowledged."

The standard theory of photoemission from a metal into the vacuum is due to Fowler (Fowler, 1931). In a gas of electrons obeying the Fermi-Dirac statistic, if photon energy is close to potential barrier $\left(\mathrm{hv} \approx \Phi_{\mathrm{B}}\right)$, the fraction $\left(\mathrm{F}_{\mathrm{e}}\right)$ of the absorbed photons, which produce photoelectrons with the appropriate energy and momenta before scattering to contribute to the photocurrent, is given by:

$$
F_{e}=\frac{\left[\left(h v-\left(\phi_{B 0}-\Delta \phi_{B}\right)\right)^{2}+\frac{(k T \pi)^{2}}{3}-2(k T)^{2} e^{-\frac{h v-\left(\phi_{B 0}-\Delta \phi_{B}\right)}{k T}}\right]}{8 k T E_{F} \log \left[1+e^{\frac{h v-\left(\phi_{B 0}-\Delta \phi_{B}\right)}{k T}}\right]}
$$

where $\mathrm{hv}$ is photons energy, $\Phi_{\mathrm{B} 0}$ is the potential barrier at zero bias, $\Delta \Phi_{\mathrm{B}}$ is the lowering due to image force effect (as we will see later), $\mathrm{E}_{\mathrm{F}}$ is the metal Fermi level, $\mathrm{k}$ is the Boltzmann's 
constant and $\mathrm{T}$ is the absolute temperature. As it is possible to see in Eq. 3, $\mathrm{F}_{\mathrm{e}}$ is strongly depending from the potential barrier height of the metal-semiconductor interface.

\subsubsection{IPE enhancement in thin metal films}

In order to study the quantum efficiency for thin metal films, the theory must be further extended, taking into account multiple reflections of the excited electrons from the surfaces of the metals film, in addition to collisions with phonons, imperfections and cold electrons. Assuming a thin metal film, a phenomenological, semiclassical, ballistic transport model for the effects of the scattering mechanisms resulting in a multiplicative factor for quantum efficiency was developed by Vickers (Vickers, 1971) and recently reviewed by Scales et al. (Scales \& Berini, 2010). According to this model the accumulated probability $P_{E}$ that the electrons will have sufficient normal kinetic energy to overcome potential barrier is given by:

$$
P_{E} \cong \frac{L_{e}}{d}\left[1-e^{-\frac{d}{L_{e}}}\right]^{\frac{1}{2}}
$$

where $d$ is the metal thickness and $L_{e}$ the metal mean free path. For example, as it can be seen by plotting Eq. 4 in Fig. 2 (assuming a copper mean free path of $45 \mathrm{~nm}$ (Chan et al., 1980a), the lower metal thickness, the higher $P_{E}$.

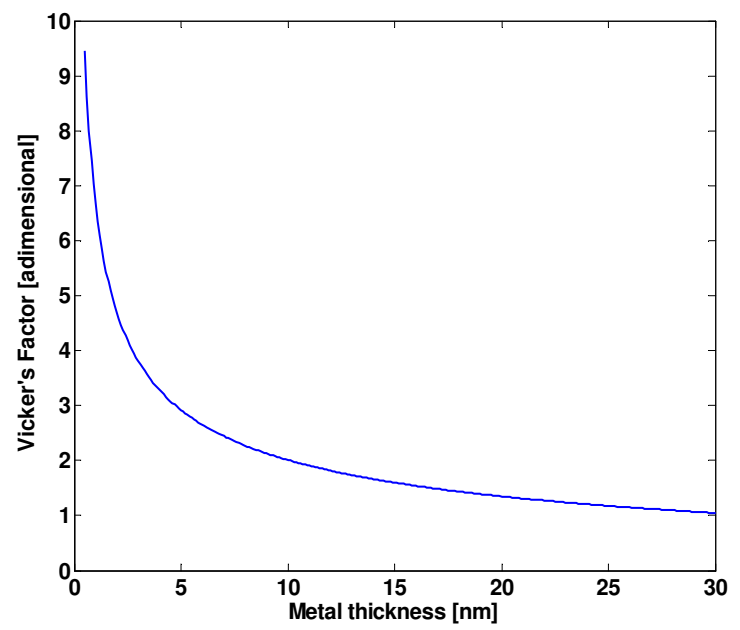

Fig. 2. Vicker's factor $P_{E}$ versus metal thickness for copper metal.

It is worth noting that in a recent work (Scales \& Berini, 2010), Scales and Berini show that a further enhancement of this probability emission can be obtained in structures realized with thin metal film buried in a semiconductor and forming two Schottky barriers.

\subsubsection{IPE enhancement by optical cavity}

The enhancement of IPE in thin metal film lead to a resulting electrode so thin to be semitransparent, producing low metal absorbance. In order to increase the absorbance in 
thin metal film, the use of a microcavity Fabry-Perot has been proposed. The sketch of proposed photodetector is shown in Fig. 3. The resonant cavity is a Fabry-Perot vertical tothe-surface structure. It is formed by a distributed Bragg reflector (DBR), a metallic top mirror and in between a Si cavity. A dielectric layer on top of the metal is generally considered for thin metal protection purpose.

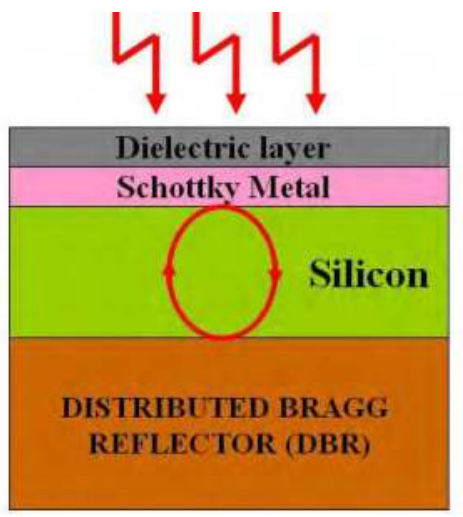

Fig. 3. Sketch of IPE photodetector based on optical cavity.

The proposed structure of Fig. 4 can be modelled by the multilayer shown in Fig. 3 and absorbance calculation can be carried out by the Transfer Matrix Method (TMM) (Muriel \& Carballar, 1997).

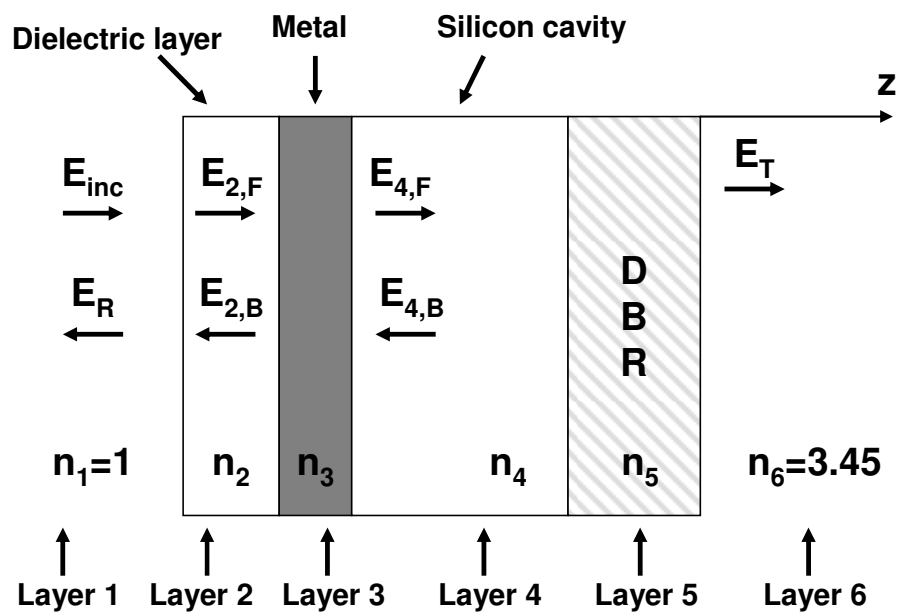

Fig. 4. Multilayer schematizing device in fig. 3 for absorbance calculation by TMM.

Normal incidence condition and the unidimensional variations of refractive index (n) along the propagation direction $\mathrm{z}$, are taken into account. Let $\mathrm{E}_{\mathrm{inc}}$ and $\mathrm{E}_{\mathrm{R}}$ be the electric field complex amplitude of the incident and reflected waves at the interface between the air and the dielectric layer, and $\mathrm{E}_{\mathrm{T}}$ the waves transmitted by final plane of structure, by TMM we obtain: 


$$
\begin{array}{r}
{\left[\begin{array}{l}
E_{\text {inc }} \\
E_{R}
\end{array}\right]=M_{\mathrm{TOT}}\left[\begin{array}{l}
E_{T} \\
0
\end{array}\right]} \\
E_{T}=\frac{1}{M_{\mathrm{TOT}_{11}}} E_{\text {inc }} \quad E_{R}=\frac{M_{\mathrm{TOT}_{21}}}{M_{\mathrm{TOT}_{11}}} E_{\text {inc }}
\end{array}
$$

where $M_{T O T_{i j}}$ are the element of the matrix $\mathrm{M}_{\mathrm{TO}}$ representing the whole multilayer:

$$
M_{\text {TOT }}=M_{1 / 2} \cdot M_{2} \cdot M_{2 / 3} \cdot M_{3} \cdot M_{3 / 4} \cdot M_{4} \cdot M_{4 / 5} \cdot M_{5} \cdot M_{5 / 6}
$$

where $M_{i / j}$ and $M_{i}$ are the interface matrix between $i$ and $j$ layer and the $i$-layer matrix, respectively, which can calculated by knowing refractive index $\left(\mathrm{n}_{\mathrm{i}}\right)$ and thickness $\left(\mathrm{d}_{\mathrm{i}}\right)$ of every $i^{\text {th }}$ layer:

$$
M_{i / j}=\frac{1}{2 n_{i}}\left(\begin{array}{ll}
n_{i}+n_{j} & n_{i}-n_{j} \\
n_{i}-n_{j} & n_{i}+n_{j}
\end{array}\right) \quad M_{i}=\left(\begin{array}{cc}
e^{j k_{0} n_{i} d_{i}} & 0 \\
0 & e^{-j k_{0} n_{i} d_{i}}
\end{array}\right)
$$

Let $E_{2, \mathrm{~F}}\left(\mathrm{E}_{4, \mathrm{~F}}\right)$ and $\mathrm{E}_{2, \mathrm{~B}}\left(\mathrm{E}_{4, \mathrm{~B}}\right)$ be the frequency domain electric field complex amplitudes of the forward and backward travelling plane waves in the layer 2 (4), by TMM we obtain:

$$
\begin{gathered}
{\left[\begin{array}{l}
E_{2, F} \\
E_{2, B}
\end{array}\right]=M_{A}\left[\begin{array}{l}
E_{T} \\
0
\end{array}\right]} \\
E_{2, F}=\frac{M_{A_{11}}}{M_{T_{11}}} E_{i n c} \quad E_{2, B}=\frac{M_{A_{21}}}{M_{T_{11}}} E_{i n c}
\end{gathered}
$$

and

$$
\begin{gathered}
{\left[\begin{array}{l}
E_{4, F} \\
E_{4, B}
\end{array}\right]=M_{B}\left[\begin{array}{l}
E_{T} \\
0
\end{array}\right]} \\
E_{4, F}=\frac{M_{B_{11}}}{M_{T_{T T_{11}}}} E_{i n c} \quad E_{4, B}=\frac{M_{B_{21}}}{M_{T_{T_{11}}}} E_{i n c}
\end{gathered}
$$

where $\mathrm{M}_{\mathrm{A}}$ is the matrix calculated from interface between protection coating and metal to the final plane, while $\mathrm{M}_{\mathrm{B}}$ is the matrix calculated from interface between metal and silicon cavity to the final plane,

$$
\begin{aligned}
& M_{A}=M_{2 / 3} \cdot M_{3} \cdot M_{3 / 4} \cdot M_{4} \cdot M_{4 / 5} \cdot M_{5} \cdot M_{5 / 6} \\
& M_{B}=M_{4} \cdot M_{4 / 5} \cdot M_{5} \cdot M_{5 / 6}
\end{aligned}
$$

The optical power is linked at the electrical field by:

$$
P=\frac{n}{2 \eta_{0}}|E|^{2}
$$

where $\eta_{0}$ is the vacuum characteristic impedance of electromagnetic waves. The total power going in $\left(\mathrm{P}_{\text {input }}\right)$ and going out $\left(\mathrm{P}_{\text {output }}\right)$ from the metal is given by: 


$$
\begin{aligned}
& P_{\text {input }}=\frac{n_{2}}{2 \eta_{0}}\left|E_{2, F}\right|^{2}+\frac{n_{4}}{2 \eta_{0}}\left|E_{4, B}\right|^{2}=\left(n_{2}\left|\frac{M_{A_{11}}}{M_{T_{O T}}}\right|^{2}+n_{4}\left|\frac{M_{B_{21}}}{M_{\mathrm{TOT}_{11}}}\right|^{2}\right) \frac{\left|E_{\text {ind }}\right|^{2}}{2 \eta_{0}} \\
& P_{\text {output }}=\frac{n_{2}}{2 \eta_{0}}\left|E_{2, B}\right|^{2}+\frac{n_{4}}{2 \eta_{0}}\left|E_{4, F}\right|^{2}=\left(n_{2}\left|\frac{M_{A_{21}}}{M_{\mathrm{TOT}_{11}}}\right|^{2}+n_{4}\left|\frac{M_{B_{11}}}{M_{\mathrm{TOT}_{11}}}\right|^{2}\right) \mid \frac{\left|E_{\text {inc }}\right|^{2}}{2 \eta_{0}}
\end{aligned}
$$

and metal absorbance can be written as (Casalino, 2006a, 2006b):

$$
A_{T}=\frac{P_{\text {input }}-P_{\text {output }}}{P_{\text {inc }}}=\left\{\left(n_{2}\left|\frac{M_{A_{11}}}{M_{T O T_{11}}}\right|^{2}+n_{4}\left|\frac{M_{B_{21}}}{M_{T O T_{11}}}\right|^{2}\right)-\left(n_{2}\left|\frac{M_{A_{21}}}{M_{T_{O O T_{11}}}}\right|^{2}+n_{4}\left|\frac{M_{B_{11}}}{M_{T_{O T_{11}}}}\right|^{2}\right)\right\}
$$

where $\mathrm{n}_{2}$ and $\mathrm{n}_{4}$ are the refractive indices of the $2^{\text {th }}$ and $4^{\text {th }}$ layer, respectively.

In a work of 2006, Casalino et al. (Casalino et al., 2006a, 2006b) proposed a methodology in order to design an optimum device, in fact with a right choice of the multilayer thicknesses a maximum in absorbance can be obtained. In the device proposed by the authors DBR is considered formed by alternate layers of $\mathrm{Si}$ and $\mathrm{SiO}_{2}$ having refractive index 3.45 and 1.45, and thickness of $340 \mathrm{~nm}$ and $270 \mathrm{~nm}$, respectively, while a metallic layer of gold, having refractive index $\mathrm{n}_{\mathrm{Au}}=0.174+\mathrm{j} 9.96$ (Chan \& Card, 1980b), mean free path $\mathrm{L}_{\mathrm{e}}=55 \mathrm{~nm}$ (Chan et al., 1980a), Fermi level $\mathrm{E}_{\mathrm{F}}=5.53 \mathrm{eV}$ (Yeh, 1988) and thickness $\mathrm{d}=32 \mathrm{~nm}$, was chosen as Schottky contact. We point out that in the simulations, semi-infinite first and last layers of air $\left(n_{1}=1\right)$ and silicon $\left(n_{6}=3.45\right)$, respectively, are considered. In Fig. 5 absorbance plotted against wavelengths is reported for the proposed device without and with DBR, showing a significant enhancement in absorbance, due to the optical cavity, of almost two order of magnitude at $1550 \mathrm{~nm}$.

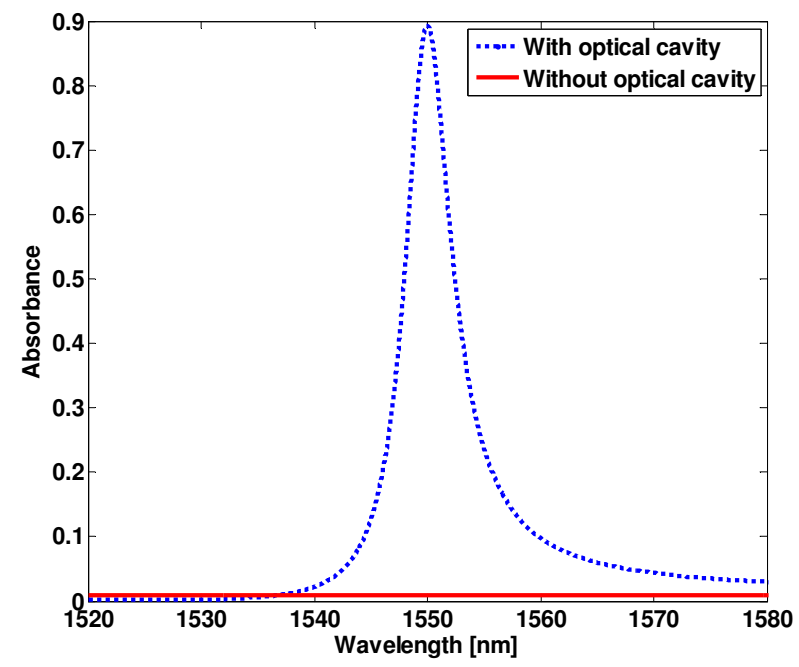

Fig. 5. Absorbance versus wavelengths for the device proposed by Casalino et al. (Casalino et al., 2006a, 2006b). 


\subsubsection{IPE enhancement by reverse voltage applied}

In order to complete the transaction of the IPE theory, the image force between an electron and the metal surface must be taken into account. Due to the image force effect a lowering $\left(\Delta \Phi_{\mathrm{B}}\right)$ and displacement $\left(\mathrm{x}_{\mathrm{m}}\right)$ of the metal-semiconductor interface potential barrier, is provided. These barrier lowering and displacement are given by (Sze, 1981):

$$
\Delta \phi_{B}=\sqrt{\frac{q}{4 \pi \varepsilon_{S i}} \frac{\left|V_{\text {Bias }}\right|}{W}} \quad x_{m}=\sqrt{\frac{q}{16 \pi \varepsilon_{S i}} \frac{W}{\left|V_{\text {Bias }}\right|}}
$$

where $\varepsilon_{\mathrm{Si}}$ is the permittivity of silicon $\left(10^{-12} \mathrm{C} / \mathrm{cmV}\right), \mathrm{W}$ is the depletion width and $\mathrm{V}_{\text {Bias }}$ the applied bias voltage.

It is worth noting that while the potential barrier lowering can be taken into account by Fowler's theory (Eq. 3), the potential barrier displacement influences the probability that an electron undergoes scattering phenomena in Si travelling from the metal-semiconductor interface to the Schottky barrier maximum. This probability can be taken into account by the barrier collection efficiency $\left(\eta_{c}\right)$ :

$$
\eta_{c}=e^{-\frac{x_{m}}{L_{s}}}
$$

where $L_{s}$ is the electron scattering length in the silicon. It is worth noting that increasing the bias voltage, a shift of Schottky barrier closer to metal/semiconductor interface is obtained. Therefore, the barrier collection efficiency increases. The improvement of the device efficiency by increasing reverse voltage has been theoretically investigated by Casalino et al. (Casalino et al., 2008b).

\subsection{Bandwidth of IPE-based devices}

The electrical properties of diodes based on Schottky junctions are determined by majority carrier phenomena, while for p-n diodes they are primarily determined by minority carriers. Therefore, the Schottky diodes can be switched faster because there are no minority carrier storage effects. The response time of Schottky barrier photodiodes can be determined by three parameters: the diffusion time in the quasi neutral region; the electrical frequency response or $\mathrm{RC}$ time required to discharge the junction capacitance through the resistance and the transit time across the depletion region. By designing the diode in such a way that depleted region length $(\mathrm{W})$ equals to the device length $(\mathrm{L})$, under suitable revere bias applied, the diffusion time can be neglected and the total frequency $\left(f_{\text {tot }}\right)$ can be written as:

$$
\frac{1}{f_{\text {tot }}}=\frac{1}{f_{\text {tr }}}+\frac{1}{f_{R C}}
$$

where $f_{t r}$ and $f_{R C}$ are the transit time and time constant limited 3-dB bandwidth, respectively.

According to the model for small signal shown in Fig. 6 (Casalino et al., 2010b), the photodetector can be schematized as current generator $\left(I_{p h}\right)$, resistance $\left(R_{j}\right)$, capacitance $\left(C_{j}\right)$ associated to the junction, series resistance $\left(R_{s}\right)$ and load resistance $\left(R_{\text {load }}\right)$ 


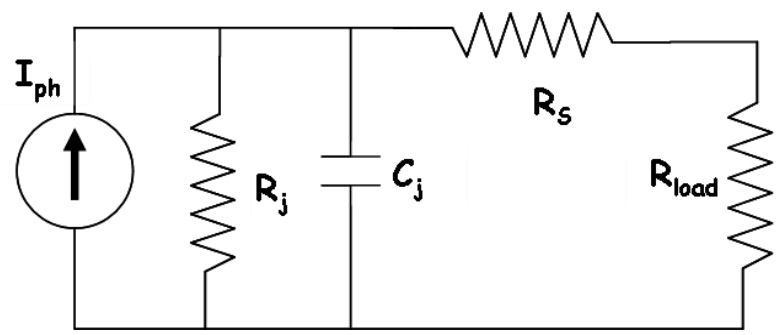

Fig. 6. Small-signal circuit associated to IPE-based device.

The RC limited bandwidth is given by:

$$
f_{R C}=\frac{1}{2 \pi\left[\left(R_{s}+R_{\text {load }}\right) / / R_{j}\right] C_{j}}=\frac{1}{2 \pi R_{\text {Tot }} C_{j}}
$$

where $R_{j}$ can be evaluated from the inverse derivative of the reverse current-voltage (I-V) electrical characteristic (tipical values are in the $M \Omega$ range) and $R_{s}$ can be extracted from the forward I-V characteristic.

For high speed applications, the load resistance $R_{L}$, tipically $50 \Omega$, is much lower than series resistance $\left(R_{\mathrm{s}}\right)$ and junction resistance $\left(\mathrm{R}_{\mathrm{j}}\right)$. Therefore, the device 3-dB frequency, becomes (Donati, 1999):

$$
f_{3 d B}=\frac{1}{2 \pi R_{s} C_{j}}
$$

Where the junction capacitor is linked to the photodetector area $\left(\mathrm{A}_{\mathrm{Ph}}\right)$ from the following formula:

$$
C_{j}=\frac{\varepsilon_{S i} A_{P h}}{W}
$$

with $\varepsilon_{\mathrm{Si}}$ is the silicon dielectric constant $\left(10^{-12} \mathrm{C} / \mathrm{cmV}\right)$. It is worth noting that when the detector area is made sufficiently small, the influence due to the capacitance is reduced, the effect of the transit time dominates and high speed operation can be reached.

The intrinsic carrier-transit time limited 3-dB bandwidth for the device is given by (Donati, 1999):

$$
f_{t r}=\frac{0.44}{t_{d}}=0.44 \frac{v_{t}}{L}
$$

where $\mathrm{v}_{\mathrm{t}}$ is the effective carrier saturation velocity $\left(10^{7} \mathrm{~cm} / \mathrm{s}\right.$ in $\left.\mathrm{Si}\right)$ and $\mathrm{L}$ is the carrier transit distance. In Fig. 7, the frequency due to RC time constant and transit time are reported as a function of the detector area for $R_{L}=50 \Omega$ an $W=1 \mu \mathrm{m}$. It is worth noting that when the detector area is made sufficiently small, i.e. smaller than $\mathrm{A}_{\mathrm{Ph}}<65 \mu \mathrm{m}^{2}$, the influence due to the capacitance is reduced of one order to magnitude with respect to the transit time, enabling device to work at $\mathrm{GHz}$ range. 


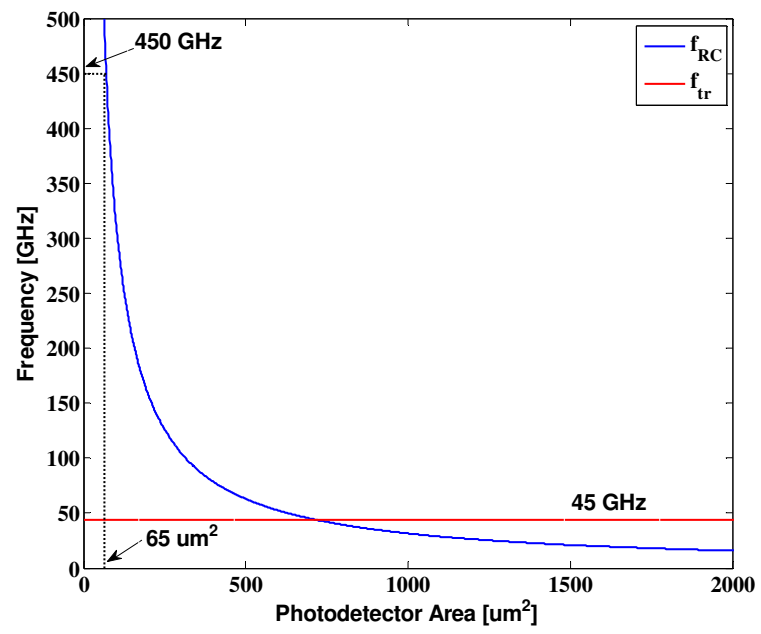

Fig. 7. Frequency due to the RC time and the transit time plotted against area detector for $\mathrm{RL}=50 \Omega$ and $\mathrm{W}=1 \mu \mathrm{m}$.

\subsection{Noise and sensitivity of IPE-based devices}

It is well known that the photodetector output is affected by a noise contribution which hinders the device sensitivity. The r.m.s. noise is due to two contributions: Johnson noise and shot noise. Johnson is the thermal noise associated to the resistance $R_{\text {load }}$ and its r.m.s value can be defined as (Donati, 1999):

$$
i_{J}=\sqrt{\frac{4 k B T}{R_{\text {load }}}}
$$

where $R_{\text {load }}$ is the load resistance, $k$ is the Boltzmann constant and $T$ is the absolute temperature. On the other hand, the shot noise is associated to the discrete nature of the total current, i.e., the sum of the signal current and dark current (Donati, 1999):

$$
i_{S}=\sqrt{2 q\left(I_{p h}+I_{d}\right) B}
$$

where $\mathrm{q}$ is the electron charge.

Because the two contributions are statistically independent their m.s. values can be added in order to get the total noise:

$$
i_{n}=\sqrt{i_{S}^{2}+i_{J}^{2}}=\sqrt{2 q\left(I_{p h}+I_{d}\right) B+\frac{4 k B T}{R}}
$$

From Eq. 23, it should be clear that shot noise can always dominate the Johnson with a right choice of $\mathrm{R}_{\text {load. }}$. Dark current of infrared photodetectors based on the IPE effect is composed by the inverse saturation current $\left(\mathrm{I}_{\mathrm{s}}\right)$ and by a background current $\left(\mathrm{I}_{\mathrm{bg}}\right)$. The background current is due to the fact that at first approximation an infrared photodetector at a temperature $\mathrm{T}$, can be view as a blackbody emitting a radiance $r(\lambda)$ according to the Planck law (Donati, 1999): 


$$
r(\lambda)=\frac{2 h v^{2}}{\lambda^{3}}\left[\frac{1}{e^{\frac{h v}{k T}}-1}\right]
$$

where hv and $\lambda$ are the photon energy and wavelength, respectively. It could be shown that this radiance is proportional to a dc background current $\left(\mathrm{I}_{\mathrm{bg}}\right)$ limiting infrared photodetector sensitivity. In order to get higher sensitivity, is necessary to reduce the background current contribute by reducing the emission radiance, i.e., by lowering the photodetector temperature (see Plank law). For this reason infrared detector needs to work at cryogenic temperature. On the other hand, photodetectors working at visible or NIR wavelengths are not able to detect blackbody emission and the Schottky junction saturation current limits the detector sensitivity. It is given by the Richardson-Dushamann equation (Yuan \& Perera, 1995):

$$
I_{s}=A_{p h} A^{* *} T^{2} e^{-\frac{\phi_{B}(V)}{k T}}
$$

where $A^{* *}=f_{p} A^{*}, A^{*}$ is the Richardson constant $\left(30 \mathrm{~A} / \mathrm{cm}^{2} \mathrm{~K}^{2}\right.$ for p-type Si and $110 \mathrm{~A} / \mathrm{cm}^{2} \mathrm{~K}^{2}$ for n-type $\mathrm{Si}$ ) (Sze, 1981), $\mathrm{f}_{\mathrm{p}}$ is the barrier escape probability which as a first approximation is given by $f_{p}(V)=\exp \left(-x_{m}(V) / L_{s}\right), L_{s}$ is the electron scattering length, $T$ is the absolute temperature and $\Phi_{\mathrm{B}}(\mathrm{V})=\Phi_{\mathrm{B} 0}-\Delta \Phi_{\mathrm{B}}(\mathrm{V})$ is the potential barrier which is the potential barrier at zero voltage minus the lowering due to the reverse bias. It is worth noting that both potential barrier and barrier escape probability are reverse voltage dependent due to force image effect. The plot of the saturation current density against reverse voltage applied for three different metal: gold $(\mathrm{Au})$, silver $(\mathrm{Ag})$ and copper $(\mathrm{Cu})$, is reported in Fig. 8 (Casalino et al., 2008b). Schottky barrier used in the simulations for Au/p-Si, Ag/p-Si and Cu/p-Si interfaces are $0.78 \mathrm{eV}, 0.78 \mathrm{eV}$ and $0.58 \mathrm{eV}$, respectively. Due to the lowest potential barrier, copper shows the highest dark current density.

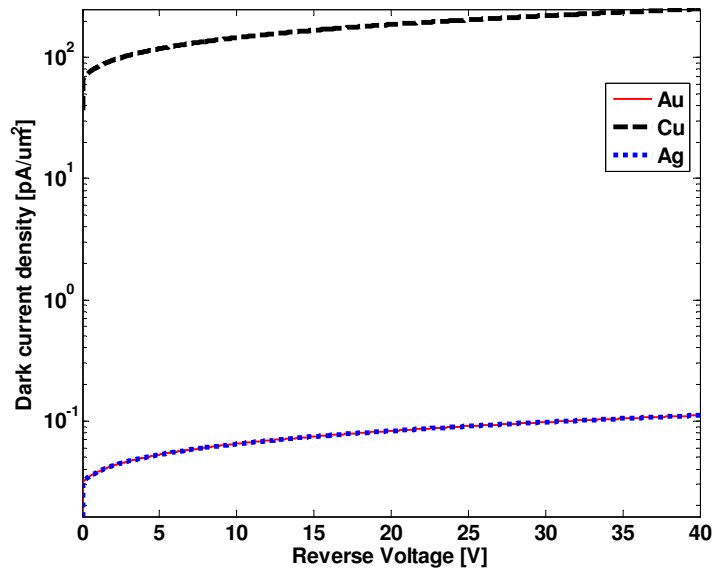

Fig. 8. Dark current density plotted against reverse voltage (semi-log scale) for three different metals: gold, silver and copper. Reprinted with permission from M. Casalino et al., "A silicon compatible resonant cavity enhanced photodetector working at $1.55 \mu \mathrm{m}$, " Semicond. Sci. Technol., 23, 075001, 2008 (doi: 10.1088/0268-1242/23/7/075001). IOP Publishing is acknowledged. 
The photodetector sensitivity is directly linked to the r.m.s. noise current and can be represented in term of a well known parameter called NEP (Noise Equivalent Power) which is defined as the ratio of r.m.s. noise to responsivity (Donati, 1999):

$$
\mathrm{NEP}=\frac{i_{n}}{\mathfrak{R}}[W]
$$

NEP represents the lowest input power giving a unit signal/noise ratio. Because higher device performances correspond to smaller NEP, it is more convenient to define its inverse: the detectivity. It can be expected that the square of the r.m.s. noise (m.s. noise) is proportional to the electrical bandwidth (B) and detector area $\left(\mathrm{A}_{\mathrm{Ph}}\right)$, for this reason in order to get a figure of merit not depending on these parameters, the detectivity is normalized to the square root of detector area and bandwidth (Donati, 1999):

$$
\mathrm{D}=\sqrt{A_{P h} \cdot B} \frac{\Re}{i_{n}}\left[\frac{c m \sqrt{H z}}{W}\right]
$$

\section{Silicon photodetectors based on IPE}

This section reviews the history and the progresses of the main structures reported in literature, starting from historical devices for imaging application at infrared wavelengths, up to new NIR devices adapted for telecommunications and power monitoring applications.

\subsection{Infrared devices for imaging application}

Schottky-barrier focal plane arrays (FPAs) are infrared imagers, fabricated by wellestablished silicon very-large-scale-integration (VLSI) process, representing one of the most effective technology for large-area high-density focal plane arrays for many near infrared (NIR, 1 to $3 \mu \mathrm{m}$ ) and medium infrared (MIR, 3 to $5 \mu \mathrm{m}$ ) applications. PtSi Schottky Barrier detectors (SBDs) represent the most established SBD technology but they must operate at 77

${ }^{\circ} \mathrm{K}$ in order to reduce the dark current density in the range of a few $\mathrm{nA} / \mathrm{cm}^{2} . \mathrm{Pd}_{2} \mathrm{Si}$ SBDs were developed for operation with passive cooling at $120^{\circ} \mathrm{K}$ in the NIR band, while IrSi SBDs have also been investigated to extend the application of Schottky-barrier focal plane arrays into the far infrared (FIR, 8 to $10 \mu \mathrm{m}$ ) spectral range.

In 1973 Shepherd and Yang (Shepherd \& Yang, 1973) proposed the concept of silicide Schottky-barrier detectors as much more reproducible alternative to HgCdTe FPAs for infrared thermal imaging. After being dormant for about ten years, extrinsic Si was reconsidered as a material for infrared imaging, especially after the invention of chargecoupled devices (CCDs) by Boyle and Smith (Boyle \& Smith, 1970). For the first time it became possible to have much more sophisticated readout schemes and both detection and readout could be implemented on one common silicon chip. Since then, the development of the Schottky-barrier technology progressed continuously and currently offers large IR image sensor formats. These trends in IR FPA development show that the IR community today prefers more producible technologies with higher uniformity to the technology based on the narrow gap semiconductors, which still have serious material problems. Such attributes as: monolithic construction, uniformity in responsivity and signal to noise (the performance of an IR system ultimately depends on the ability to compensate the non uniformity of an FPA using external electronics and a variety of temperature references), and absence of discernible 1/f noise; make Schottky-barrier devices a formidable contender to the 
mainstream infrared systems and applications. (Shepherd, 1984; Shepherd, 1988; Kosonocky, 1991; Kosonocky, 1992; Shepherd, 1998). In the early years, the development of SBD FPA technology progressed from the demonstration of the initial concepts in the 1970's (Kohn et al., 1975; Capone et al., 1978; Kosonocky et al., 1978; Shepherd et al., 1979) to the development of high resolution scanning and staring devices in the 1980's and in the 1990's, that were at the basis of many applications for infrared imaging in the NIR, MIR and FIR bands. The first Schottky-barrier FPAs were made with thick $\mathrm{Pd}_{2} \mathrm{Si}$ or PtSi detectors using about $600 \AA$ of deposited palladium or platinum. These FPAs exhibited relatively small photoresponse. More than an order of magnitude improvement in photoresponse was demonstrated in 1980 with 50×50-element FPAs constructed with thin PtSi SBDs at the David Sarnoff Research Center (Taylor et al, 1980; Kosonocky et al., 1980). The SBDs in this FPA had an optical cavity in the form of a thin $(20-40 \AA)$ PtSi layer separated from an aluminium reflector by a layer of deposited $\mathrm{SiO}_{2}$. The general concept of thin SBD with optical cavity was first described in 1973 by Archer and Cohen for SBDs in the form of Au on p-type Si (Archer \& Cohen, 1973). The improved PtSi SBD structure was further developed and from 1980 to 1985 the fabrication process for PtSi SBDs was optimized at Sarnoff with the development of $32 \times 63,64 \times 128$ and $160 \times 244$ IR-CCD FPAs (Elabd et al., 1982; Kosonocky, 1985). Similar PtSi SBDs characteristics were also reported in the same years by Mitsubishi Corporation, Fujitsu, NEC, EG\&G Reticon, Hughes, Loral Fairchild and Kodak.

As already discussed, the most popular Schottky-barrier detector is the PtSi detector, which can be used for the detection in the 3-5 $\mu \mathrm{m}$ spectral range (Kimata \& Tsubouchi, 1995; Kimata, 2000). Radiation is transmitted through the p-type silicon and is absorbed in the metal PtSi (not in the semiconductor), producing hot holes, which are then emitted over the potential barrier into the silicon, leaving the silicide charged negatively. Negative charge of silicide is transferred to a CCD by the direct charge injection method (see Fig. 9).

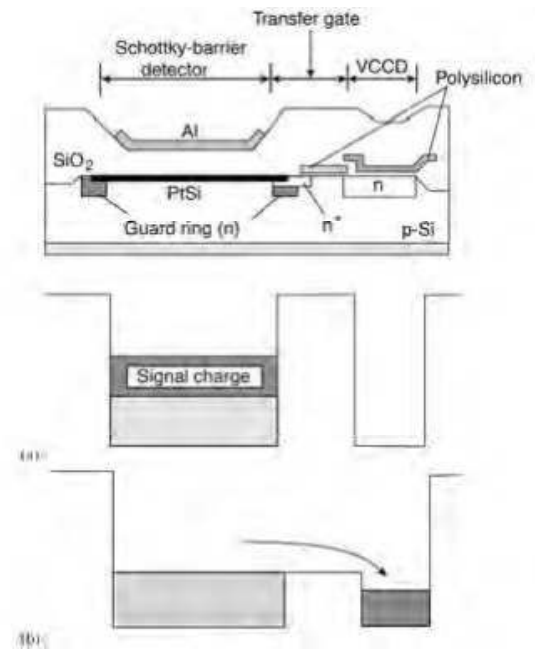

Fig. 9. Typical construction and operation of PtSi Schottky-barrier IR FPA designed with interline transfer CCD readout architecture. (a) and (b) show the potential diagrams in the integration and readout operations, respectively (Kimata, 1995, 1998). Reprinted with permission from M. Kimata, "PtSi Schottky-barrier infrared focal plane arrays," OptoElectronics Review, 6, 1, 1998. 
The effective quantum efficiency in the 3-5 $\mu \mathrm{m}$ window is very low, of the order of $1 \%$, but useful sensitivity is obtained by means of near full frame integration in area arrays. The quantum efficiency has been improved by thinning PtSi film and implementation of an optical cavity. Due to very low quantum efficiency, the operating temperature of Schottkybarrier photoemissive detectors is lower than another types of IR photon detectors (Rogalsky, 1999).

Schottky photoemission is independent of such factors as semiconductor doping, minority carrier lifetime, and alloy composition, and, as a result of this, has spatial uniformity characteristics that are far superior to those of other detector technologies. Uniformity is only limited by the geometric definition of the detectors. The fundamental source of dark current in the devices is thermionic emission of holes over the potential barrier and its magnitude is given by Richardson's equation (Sze, 1982). The cooling requirements of photoemissive detectors are comparable to the extrinsic devices, and while an extension of the technology to the long wavelength band is possible using IrSi (see Fig. 10) this will require cooling below $77^{\circ} \mathrm{K}$ (Shepherd, 1988).

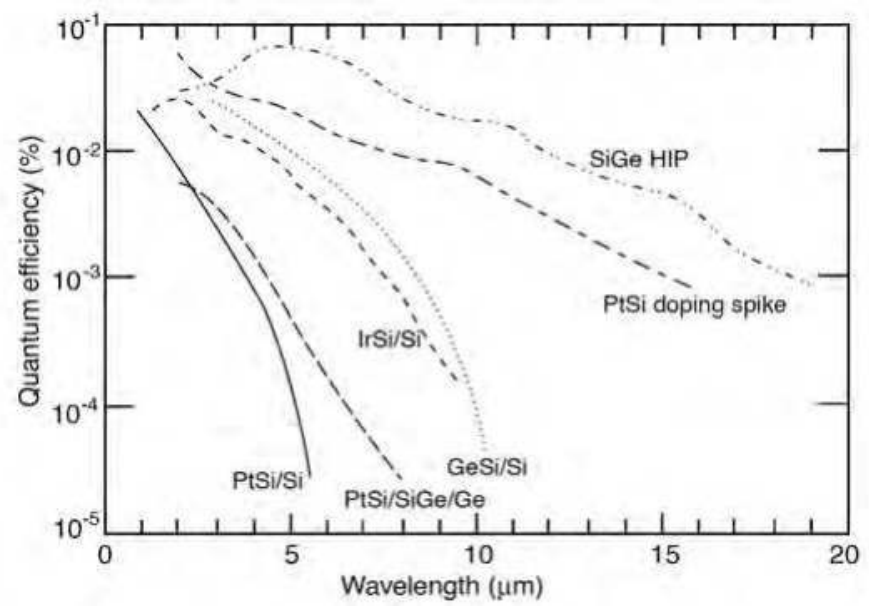

Fig. 10. Comparison of various infrared detectors based on IPE for PtSi, IrSi, PtSi/SiGe, PtSi doping spike, and SiGe/Si HIP (Kimata, 2000). Reprinted with permission from M. Kimata, Metal silicide Schottky infrared detector arrays. In: Infrared Detectors and Emitters: Materials and Devices, Kluwer Academic Publishers, Boston, USA, 2000.

The Schottky-barrier detector is typically operated in backside illumination mode. The quantum efficiency has been improved by thinning PtSi film. The thinning is effective down to the PtSi thickness of $2 \mathrm{~nm}$. Another means of improving responsivity is implementation of an optical cavity. The optical cavity structure consists of the metal reflector and the dielectric film between the reflector and metal electrode of the Schottky-barrier diode. According to fundamental optical theory, the effect of the optical cavity depends on the thickness and refractive index of the dielectric films, and the wavelength (Kurianski et al., 1989). The main advantage of the Schottky-barrier detectors is that they can be fabricated as monolithic arrays in a standard silicon VLSI process. Typically, the silicon array is completed up to the $\mathrm{Al}$ metallization al step. A Schottky-contact mask is used to open $\mathrm{SiO}_{2}$ 
surface to p-type $<100>$ silicon (with resisitivity $30-50 \Omega / \mathrm{cm}$ ) at the Schottky-barrier detector location. In the case of PtSi detectors, a very thin layer of $\mathrm{Pt}(1-2 \mathrm{~nm})$ is deposited and sintered (annealed at a temperature in the range of $300-600^{\circ} \mathrm{C}$ ) to form $\mathrm{PtSi}$ and the unreacted $\mathrm{Pt}$ on the $\mathrm{SiO}_{2}$ surfaces is removed by dip etching in hot aqua regia. The Schottkybarrier structure is then completed by a deposition of a suitable dielectric (usually $\mathrm{SiO}_{2}$ ) for forming the resonant cavity, removing this dielectric outside the Schottky-barrier regions, and depositing and defining $\mathrm{Al}$ for the detector reflector and the interconnects of the $\mathrm{Si}$ readout multiplexer. In the case of the $10 \mu \mathrm{m}$ IrSi Schottky-barrier detectors, the IrSi was formed by in situ vacuum annealing and the unreacted Ir was removed by reactive ion etching. The progress of the Schottky-barrier FPA technology has been constant (Kimata et al., 1998). At the present time Schottky-barrier FPAs represent the most advanced FPAs technology for medium wavelength applications (see Table 1).

\begin{tabular}{llllllll}
\hline Array size & Readout & $\begin{array}{l}\text { Pixel size } \\
\left(\mu \mathrm{m}^{2}\right)\end{array}$ & $\begin{array}{l}\text { Fill } \\
\text { factor } \\
(\%)\end{array}$ & $\begin{array}{l}\text { Saturation } \\
(\mathrm{e})\end{array}$ & $\begin{array}{l}\text { NEDT } /(f / \#) \\
(\mathrm{K})\end{array}$ & Year & Company \\
\hline $512 \times 512$ & CSD & $26 \times 20$ & 39 & $1.3 \times 10^{6}$ & $0.07(1.2)$ & 1987 & Mitsubishi \\
$512 \times 488$ & IL-CCD & $31.5 \times 25$ & 36 & $5.5 \times 10^{5}$ & $0.07(1.8)$ & 1989 & Fairchild \\
$512 \times 512$ & LACA & $30 \times 30$ & 54 & $4.0 \times 10^{5}$ & $0.10(1.8)$ & 1989 & RADC \\
$640 \times 486$ & IL-CCD & $25 \times 25$ & 54 & $5.5 \times 10^{5}$ & $0.10(2.8)$ & 1990 & Kodak \\
$640 \times 480$ & MOS & $24 \times 24$ & 38 & $1.5 \times 10^{6}$ & $0.06(1.0)$ & 1990 & Sarnoff \\
$640 \times 488$ & IL-CCD & $21 \times 21$ & 40 & $5.0 \times 10^{5}$ & $0.10(1.0)$ & 1991 & NEC \\
$640 \times 480$ & HB $/$ MOS & $20 \times 20$ & 80 & $7.5 \times 10^{5}$ & $0.10(2.0)$ & 1991 & Hughes \\
$1040 \times 1040$ & CSD & $17 \times 17$ & 53 & $1.6 \times 10^{6}$ & $0.10(1.2)$ & 1991 & Mitsubishi \\
$512 \times 512$ & CSD & $26 \times 20$ & 71 & $2.9 \times 10^{6}$ & $0.03(1.2)$ & 1992 & Mitsubishi \\
$656 \times 492$ & IL-CCD & $26.5 \times 26.5$ & 46 & $8.0 \times 10^{5}$ & $0.06(1.8)$ & 1993 & Fairchild \\
$811 \times 508$ & IL-CCD & $18 \times 21$ & 38 & $7.5 \times 10^{5}$ & $0.06(1.2)$ & 1996 & Nikon \\
$801 \times 512$ & CSD & $17 \times 20$ & 61 & $2.1 \times 10^{6}$ & $0.04(1.2)$ & 1997 & Mitsubishi \\
$1968 \times 1968$ & IL-CCD & $30 \times 30$ & - & - & - & 1998 & Fairchild \\
\hline
\end{tabular}

Table 1. Specifications and performances of typical PtSi Schottky-barrier FPAs (Kimata, 2000). Reprinted with permission from M. Kimata, Metal silicide Schottky infrared detector arrays. In: Infrared Detectors and Emitters: Materials and Devices, Kluwer Academic Publishers, Boston, USA, 2000.

The details of the geometry, and the method of charge transfer differ for different manufacturers. The design of a staring Schottky-barrier FPAs for given pixel size and design rules, involves a trade-off between the charge handling capacity and the fill factor. Most of the reported Schottky-barrier FPAs have the interline transfer CCD architecture. The typical cross section view of the pixel and its operation in interline transfer CCD architecture is shown in Fig. 9. The pixel consists of a Schottky-barrier detector with an optical cavity, a transfer gate, and a stage of vertical CCD. The n-type guard ring on the periphery of the Schottky-barrier diode reduces the edge electric field and suppresses dark current. The effective detector area is determined by the inner edge of the guard ring. The transfer gate is an enhancement MOS transistor. The connection between detector and the transfer gate is made by an $n+$ diffusion. A buried-channel CCD is used for the vertical transfer. During the optical integration time the surface-channel transfer gate is biased into accumulation. The Schottky-barrier detector is isolated from the CCD register in this condition. The IR 
radiation generates hot holes in the $\mathrm{PtSi}$ film and some of the excited hot holes are emitted into the silicon substrate leaving excess electrons in the PtSi electrode. This lowers the electrical potential of the PtSi electrode. At the end of the integration time, the transfer gate is pulsed-on to read out the signal electrons from the detector to the CCD register. At the same time, the electrical potential of the PtSi electrode is reset to the channel level of the transfer gate. A unique feature of the Schottky-barrier IR FPAs is the built-in blooming control (blooming is a form of crosstalk in which a well saturates and the electrons spill over into neighbouring pixels). A strong illumination forward biases the detector and no further electrons are accumulated at the detector. The small negative voltage developed at the detector is not sufficient to forward bias the guard ring to the extent that electrons are injected to the CCD register through the silicon region under the transfer gate. Therefore, unless the vertical CCD has an insufficient charge handling capacity, blooming is suppressed perfectly in the Schottky-barrier IR FPA. The responsivity of the FPAs is proportional to their fill factor, and improvement in the fill factor has been one of the most important issues in the development of imagers. For improving the fill factor a readout architecture called the charge sweep device (CSD) developed by Mitsubishi Corporation is also used. Kimata and co-workers have developed a series of IR image sensors with the CSD readout architecture with array sizes from $256 \times 256$ to $1040 \times 1040$ elements. Specifications and performance of these devices are summarised in Table 2. The effectiveness of this readout architecture is enhanced as the design rule becomes finer. Using a $1.2 \mu \mathrm{m}$ CSD technology, a large fill factor of $71 \%$ was achieved with a $26 \times 20 \mu \mathrm{m}^{2}$ pixel in the $512 \times 512$ monolithic structure (Yagi et al., 1994). The noise equivalent temperature difference (NETD) was estimated as $0.033^{\circ} \mathrm{K}$ at $300^{\circ} \mathrm{K}$. The $1040 \times 1040$ element CSD FPA has the smallest pixel size $\left(17 \times 17 \mu \mathrm{m}^{2}\right)$ among two-dimensional IR FPAs. The pixel was constructed with $1.5 \mu \mathrm{m}$

\begin{tabular}{|c|c|c|c|c|c|c|}
\hline Array size & $256 \times 256$ & $512 \times 512$ & $512 \times 512$ & $512 \times 512$ & $801 \times 512$ & $1040 \times 1040$ \\
\hline Pixel size $\left(\mu \mathrm{m}^{2}\right)$ & $26 \times 26$ & $26 \times 20$ & $26 \times 20$ & $26 \times 20$ & $17 \times 20$ & $17 \times 17$ \\
\hline Fill factor $(\%)$ & 58 & 39 & 58 & 71 & 61 & 53 \\
\hline Chip size $\left(\mathrm{mm}^{2}\right)$ & $9.9 \times 8.3$ & $16 \times 12$ & $16 \times 12$ & $16 \times 12$ & $16 \times 12$ & $20.6 \times 19.4$ \\
\hline Pixel capacitor & Normal & Normal & High-C & High-C & High-C & High-C \\
\hline CSD & 4-phase & 4-phase & 4-phase & 4-phase & 4-phase & 4-phase \\
\hline HCCD & 4-phase & 4-phase & 4-phase & 4-phase & 4-phase & 4-phase \\
\hline Number of outputs & 1 & 1 & 1 & 1 & 1 & 4 \\
\hline Interface & $\begin{array}{l}\text { Non } \\
\text { integration }\end{array}$ & $\begin{array}{l}\text { Field } \\
\text { integration }\end{array}$ & $\begin{array}{l}\text { Frame/Field } \\
\text { integration }\end{array}$ & $\begin{array}{l}\text { Frame/Field } \\
\text { integration }\end{array}$ & Flexible & $\begin{array}{l}\text { Field } \\
\text { integration }\end{array}$ \\
\hline $\begin{array}{l}\text { Number of } 1 / 0 \\
\text { pins }\end{array}$ & 30 & 30 & 30 & 30 & 25 & 40 \\
\hline \multirow[t]{3}{*}{ Process technology } & NMOS & NMOS & NMOS & NMOS & CMOS & NMOS/ \\
\hline & $\mathrm{CCD}$ & $\mathrm{CCD}$ & $\mathrm{CCD}$ & $\mathrm{CCD}$ & $\mathrm{CCD}$ & $\mathrm{CCD}$ \\
\hline & 2 poly $/ 2 \mathrm{Al}$ & 2 poly $/ 2 \mathrm{Al}$ & 2 poly $/ 2 \mathrm{Al}$ & 2 poly $/ 2 \mathrm{Al}$ & 2 poly $/ 2 \mathrm{Al}$ & 2 poly $/ 2 \mathrm{Al}$ \\
\hline Design rule $(\mu \mathrm{m})$ & 1.5 & 2 & 1.5 & 1,2 & 1.2 & 1.5 \\
\hline $\begin{array}{l}\text { Thermal response } \\
(\mathrm{ke} / \mathrm{K})\end{array}$ & - & 13 & - & 32 & 22 & 9.6 \\
\hline Saturation (e) & $0.7 \times 10^{6}$ & $1.2 \times 10^{6}$ & - & $2.9 \times 10^{6}$ & $2.1 \times 10^{6}$ & $1.6 \times 10^{6}$ \\
\hline NETD $(K)$ & - & 0.07 & - & 0.033 & 0.037 & 0.1 \\
\hline
\end{tabular}

Table 2. Specifications and performance of 2-D PtSi Schottky-barrier FPAs with CSD readout (Kimata, 1998). Reprinted with permission from M. Kimata, "PtSi Schottky-barrier infrared focal plane arrays," Opto-Electronics Review, 6, 1, 1998. 
design rules and has $53 \%$ fill factor (Kimata et al., 1992). If the signal charges of $1040 \times 1040$ pixels are readout from one output port at the TV compatible frame rate, an unrealistic pixel rate of about $40 \mathrm{MHz}$ is required. Therefore, a 4-output chip design was adopted (Shiraishi et al., 1996). The array of $1040 \times 1040$ pixels is divided into four blocks of $520 \times 520$ pixels. Each block has a horizontal CCD and a floating diffusion amplifier. One-million pixel data at a 30 $\mathrm{Hz}$ frame rate can be readout by operating each horizontal CCD at a $10 \mathrm{MHz}$ clock frequency. The NEDT of $1040 \times 1040$ element FPA at $300{ }^{\circ} \mathrm{K}$ with a $30 \mathrm{~Hz}$ frame is $0.1{ }^{\circ} \mathrm{K}$. More recently, a high-performance $801 \times 512$-element PtSi Schottky-barrier infrared image sensor has been developed with an enhanced CSD readout architecture (Inoue et al., 1997; Kimata et al., 1997). The developed image sensor has a large fill factor of $61 \%$ in spite of a small pixel size of $17 \times 20 \mu \mathrm{m}^{2}$. The NEDT was $0.037{ }^{\circ} \mathrm{K}$ at $300{ }^{\circ} \mathrm{K}$. The total power consumption of the device was less than $50 \mathrm{~mW}$. Current PtSi Schottky barrier FPAs are mainly manufactured in $150 \mathrm{~mm}$ wafer process lines with around $1 \mu \mathrm{m}$ lithography technologies; the most advanced Si technology offers $200 \mathrm{~mm}$ wafers process with $0.25 \mu \mathrm{m}$ design rules. Furthermore, $300 \mathrm{~mm}$ Si wafer processes with $0.15 \mu \mathrm{m}$ fine patterns will soon available. However, the performance of monolithic PtSi Schottky-barrier FPAs has reached a plateau, and a slow progress from now on is expected.

\subsection{IPE-based NIR devices}

In this section, the main Near-Infrared silicon photodetectors structures based on the aforementioned IPE effect will be reviewed. The simplest detectors consist of a metal layer on a semiconductor forming a Schottky contact at the material interface, with the Schottky barrier energy $\Phi_{\mathrm{B}}$ determined by the materials (Sze, 1981). If an infrared radiation reaches metal/semiconductor interface, the conduction electrons inside the metal can absorb photons gaining sufficient energy. These excited (hot) electrons are able to cross over the Schottky barrier, sweep out the depletion region of the semiconductor, and be collected as a photocurrent under reverse bias operation from an ohmic semiconductor-metal interface. In practice, p-type silicon is often used as the semiconductor because Schottky barriers are lower thereupon than on n-type silicon, allowing detection at longer wavelengths. The IPEeffect, as described in the section 2.1, is very fast allowing to reach high data rates. On the other hand, it is inherently weak so several photodetector designs have been proposed for achieving a suitable quantum efficiency. Elabd et al. proposed to use a very thin metal film (about $2 \mathrm{~nm}$ ) to increase the escape probability of hot carriers due to their multiple reflections inside the metal film (Elabd et al., 1982). In particular, the proposed Schottky photodetector was characterized by a responsivity of about $250 \mathrm{~mA} / \mathrm{W}$ for a wavelength $\lambda=1500 \mathrm{~nm}$. However, since the volume in which the photons interact with electrons in the metal is very small, only a small fraction of the incident photons actually causes photoemission. Several solutions have been proposed to enhance the efficiency of the IPE process. For example, in the 2001 Wang's group (Lee et al., 2001) investigated the spectral responsivity of Al-porous silicon Schottky barrier photodetectors in the wavelength range 0.4-1.7 $\mu \mathrm{m}$. The structure of the PS photodetector was Al (finger type)/PS/Si/Al (ohmic), and the active area was $18 \mathrm{~mm}^{2}$. The photodetectors show strong photoresponsivity in both the visible and the infrared bands, especially at $1.55 \mu \mathrm{m}$. The photocurrent can reach $1.8 \mathrm{~mA}$ at a reverse bias of $6 \mathrm{~V}$ under illumination by a $1.55-\mu \mathrm{m}, 10-\mathrm{mW}$ laser diode. The corresponding quantum efficiency is $14.4 \%$; this high value comes from a very high surfacearea-to-volume ratio, of the order of $200-800 \mathrm{~m}^{2} / \mathrm{cm}^{3}$ of porous Si. The dark current is $\sim 5 \mu \mathrm{A}$ 
at -10 V. Recently, Casalino et al. (Casalino et al., 2008a, 2010b) propose to enhance the IPE absorption by a resonant cavity effect. The conceptual scheme of the proposed device in shown in Fig. 11.

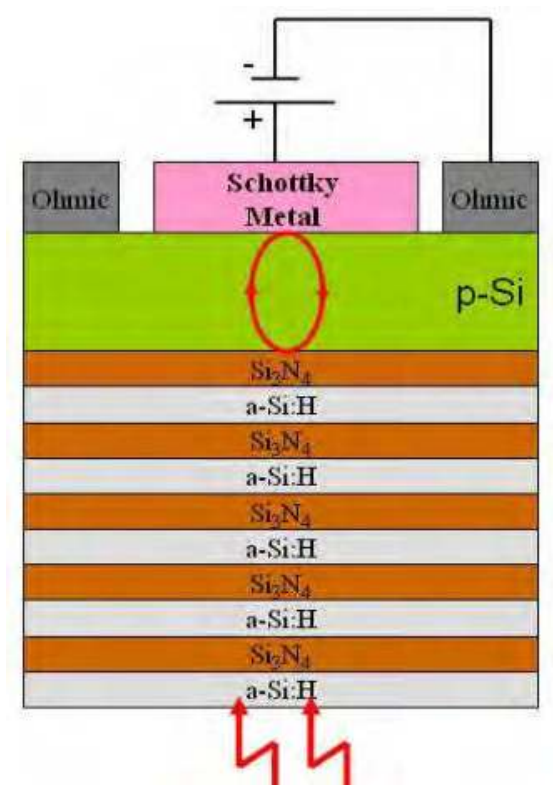

Fig. 11. Schematic cross section of the photodetector proposed by Casalino et al. (Casalino et al., 2010b) in 2010 .

The resonant cavity is a vertical-to-the-surface Fabry-Perot structure. It is formed by a buried reflector, a top mirror interface and, in the middle, a silicon cavity. The buried reflector is a Bragg mirror, realized by alternating layers of amorphous hydrogenated silicon (a-Si:H) and silicon nitride $\left(\mathrm{Si}_{3} \mathrm{~N}_{4}\right)$. A Schottky metal layer $(\mathrm{Cu})$, working both as active (absorbing) layer and as cavity mirror, is deposited above the silicon layer. The room temperature responsivity measurements on the device return a peak value of about 2.3 $\mu \mathrm{A} / \mathrm{W}$ and $4.3 \mu \mathrm{A} / \mathrm{W}$, respectively for $0 \mathrm{~V}$ and $-10 \mathrm{mV}$ of reverse bias applied (Casalino et al., 2008a). In (Casalino et al., 2010b) the authors propose both to scaling down and optimize the same device described in (Casalino et al., 2008a). In particular, the cavity finesse was increased allowing to reach a responsivity of $8 \mu \mathrm{A} / \mathrm{W}$ for a reverse bias of $100 \mathrm{mV}$.

A substantial enhancement of the IPE process efficiency has been achieved increasing the interaction of light with the metal in the vicinity of the interface by the confinement of the infrared radiation into a silicon waveguide. This solution has effectively proven that Schottky diode photodetectors are good candidate for the highly integrated photonics circuits. An example of this approach has recently demonstrated by Coppola's group (Casalino et al., 2010c). The proposed device is schematically illustrated in Fig. 12. A rib waveguide was terminated on a deep trench that reaches down the buried oxide layer of the SOI wafer. A Cu/p-Si Schottky contact was fabricated on the vertical surface of the deep trench. 


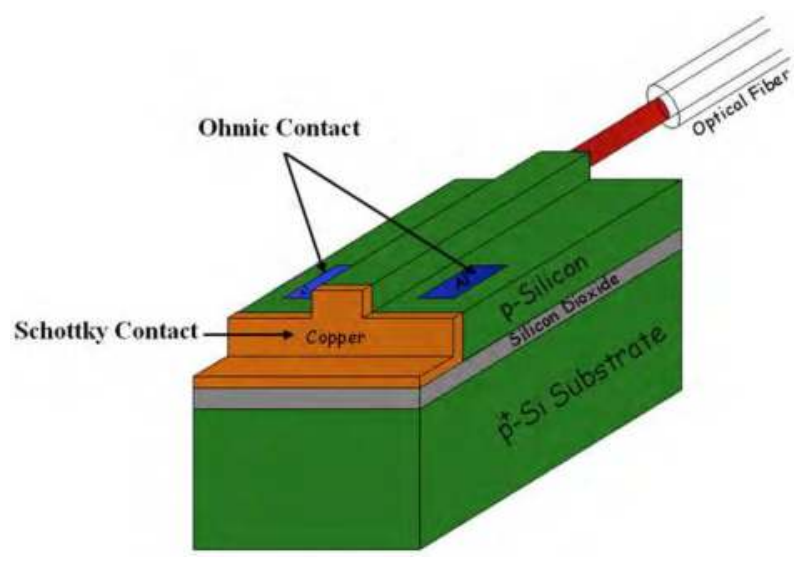

Fig. 12. Schematic view of the $\mathrm{Cu} / \mathrm{p}$-Si Schottky barrier-based integrated photodetector proposed by Casalino et al. (Casalino et al., 2010c). Reprinted with permission from M. Casalino et al., "Cu/p-Si Schottky barrier-based near infrared photodetector integrated with a silicon-on-insulator waveguide," Appl. Phys. Lett., 96, 241112. Copyright 2010 American Institute of Physics.

By means of this technological solution a very narrow semiconductor/metal barrier transverse to the optical field coming out from the waveguide has been achieved. The integrated photodetector was characterized by a responsivity of $0.08 \mathrm{~mA} / \mathrm{W}$ at a wavelength of $1550 \mathrm{~nm}$ with an reverse bias of $-1 \mathrm{~V}$. Measured dark current at $-1 \mathrm{~V}$ was about $10 \mathrm{nA}$. Moreover, the authors assert that the thinness of $\mathrm{Cu} / \mathrm{p}-\mathrm{Si}$ Schottky barrier could enable a speed operation in the gigahertz range. An indirect evaluation of the bandwidth of the detector was reported to confirm the operation speed potentialities. A bandwidth of about $3 \mathrm{GHz}$ was measured by Zhu et al. in (Zhu et al., 2008a) on a Schottky barrier based integrated photodetector, where the junction was achieved by a nickel silicide layer ( $\mathrm{NiSi}_{2}$ ) on silicon (Zhu et al., 2008b, 2008c)(Fig. 13).

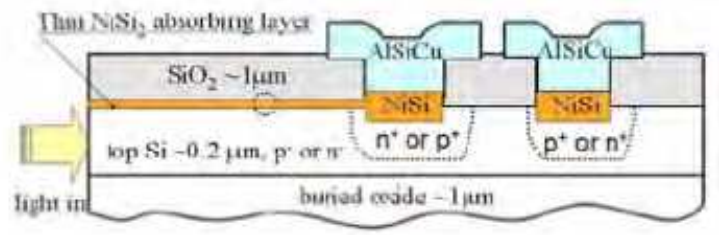

Fig. 13. Schematic structure of waveguide-based silicide Schottky-barrier photodetector proposed by Zhu et al. (Zhu et al., 2008b, 2008a). Reprinted with permission from S. Zhu et al., "Near-infrared waveguide-based nickel silicide Schottky-barrier photodetector for optical communications," Appl. Phys. Lett., 92, 081103. Copyright 2008 American Institute of Physics.

In particular, the authors proposed the lengthening of a thin silicide layer on the surface of a SOI waveguide to achieve both a suitable optical absorption and an efficient photoexcitation of metal electrons or holes across the silicide/Si interface. A detailed analysis was reported 
on the influence of the silicide layer dimension on the performances of both $\mathrm{NiSi}_{2} / \mathrm{p}-\mathrm{Si}$ and $\mathrm{NiSi}_{2} / \mathrm{n}$-Si diodes. The overall performances of the $\mathrm{NiSi}_{2} / \mathrm{p}-\mathrm{Si}$ structure have been resulted better than that relative to the $\mathrm{NiSi}_{2} / \mathrm{n}$-Si interface, due to the lower Schottky barrier height of the latter structure. In particular, a responsivity of about $4.6 \mathrm{~mA} / \mathrm{W}$ at a wavelength of $1550 \mathrm{~nm}$ and a reverse bias of $-1 \mathrm{~V}$ was estimated for the $\mathrm{NiSi}_{2} / \mathrm{p}-\mathrm{Si}$ diode against the value of $2.3 \mathrm{~mA} / \mathrm{W}$ of the $\mathrm{NiSi}_{2} / \mathrm{n}-\mathrm{Si}$ junction. Moreover, also the $3 \mathrm{nA}$ of the measured dark current can be considered acceptable.

In order to increase further the capability of IPE-based silicon photodetector to detect longwavelength (infrared) photons, the possibility to use the concept of surface plasmon polaritons (SPPs) has been explored. SPP are TM-polarized electromagnetic waves trapped at or guided along a metal-dielectric interface. This effect was discovered several decades ago but attention has been renewed by the phenomena of enhanced optical transmission through metallic films with nanostructure (Reather, 1988; Ebbesen et al., 1998). In fact, SPPs are shorter in wavelength than the incident light providing a significant increase in spatial confinement and local field intensity. In other words, while optical systems are basically diffraction limited, surface plasmon polaritons allow a tight localization of optical field to strongly subwavelength dimensions at the metal-dielectric interface (Barnes et al., 2003; Maier, 2006). Such property means that the infrared light is directly guided toward the active area of the IPE detector, confining the optical power at the boundary between the materials forming the Schottky contact, thereby increasing the interaction of light with the metal in the vicinity of the interface where the photoemission process takes place. Berini's group at University of Ottawa has recently applied these concepts confirming that the high light confinement of the SPPs structures can significantly improve the detection capability of the IPE-based photodetector integrated on Si wafers. In particular, Scales et al. in (Scales et al., 2004, 2009) described a Schottky diode photodetector obtained embedding a metal stripe of finite width in a homogeneous dielectric cladding (symmetric structure). The proposed device (see Fig. 14) was characterized by a responsivity of about $0.1 \mathrm{~A} / \mathrm{W}$, a dark currents of $21 \mathrm{nA}$, and minimum detectable powers of $-22 \mathrm{dBm}$ at a wavelength $\lambda=1550 \mathrm{~nm}$.

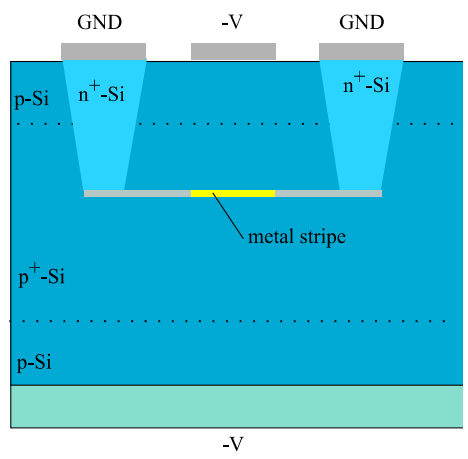

Fig. 14. SPPs Schottky detector based on a metal stripe surrounded by silicon.

An accurate investigation of the performance of the same device for different wavelengths and for several metals forming Schottky contacts were carried out in (Scales et al., 2011). It is worth noting that in these symmetric structures the realization of a thin metal film buried in a semiconductor become the fabrication process more complicated, however, despite of this drawback, the IPE is enhanced due to emission carriers occurring through two Schottky 
barriers (Scales \& Berini, 2010). In order to simplify the fabrication process and to obtain a very short device, Berini's group has proposed an asymmetric SPPs-based photodetector (Akbari et al., 2009, 2010). The proposed structure supports highly confined and highly attenuated SPP modes; this latter feature allows to fabricate shorter devices compared to the symmetric photodetectors. The device, sketched in Fig. 15, consists of a metal stripe cladded at the bottom by a layer of Silicon and covered by air and exhibits for a wavelength $\lambda=1280 \mathrm{~nm}$ a maximum value of responsivity of about $1 \mathrm{~mA} / \mathrm{W}$ with a dark current of $6 \mu \mathrm{A}$ (Akbari et al., 2010).

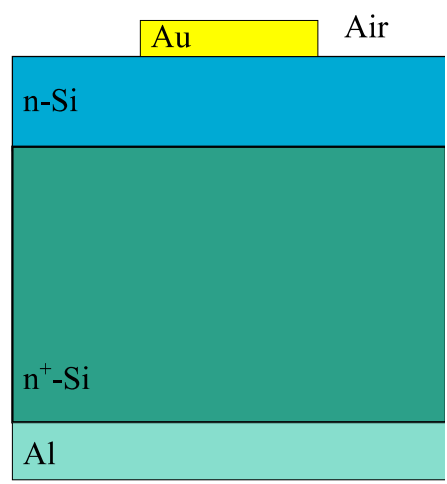

Fig. 15. Cross-section of the aymmetric SPPs Schottky detector proposed in (Akbari et al., 2010).

A detailed simulation analysis performed on asymmetric Schottky detector shows that a significant enhancement in the responsivity can be achieved for a thin metal stripe (about 5 $\mathrm{nm}$ ) due to multiple internal reflections of excited carriers (Akbari et al., 2009). In particular, authors report that the enhancement is more noticeable for thin metal stripe on p-Si compared to device on $\mathrm{n}-\mathrm{Si}$. In this case, the energy range over which the hot electrons can experience multiple reflections is very small because of the larger Schottky barrier height. Finally, the same group has recently demonstrated that a considerable increase in responsivity can be reached with strong applied reverse bias (Olivieri et al., 2010). In particular, authors driving a no optimized detector like that shown in Fig. 15 into breakdown $(\mathrm{V} \sim-210 \mathrm{~V})$, such that internal electronic gain is obtained by carrier multiplication, obtaining a responsivity of $2.35 \mathrm{~mA} / \mathrm{W}$.

As mentioned above the possibility to achieve a strong light confinement implies both an improvement of responsivity and an important advancement in device miniaturization enabling the realization of on-chip photodetectors on the nanoscale. In this contest, Goykhman et al. in (Goykhmanet al., 2011) have been characterized a nanoscale silicon surface-plasmon Schottky detector shown in Fig. 16.

The detector was fabricated employing a self-aligned approach of local-oxidation of silicon (LOCOS) on silicon on insulator substrate. This approach has been proved useful for fabricating in the same process both a low-loss bus photonic waveguide and the detector. Actually, the oxide spacers effectively define the nanometric area of metal-silicon interface and thus allow avoiding lateral misalignment between the silicon surface and the metal layer to form a Schottky contact. The so realized photodetector was characterized by a 
responsivity $0.25,1.4$, and $13.3 \mathrm{~mA} / \mathrm{W}$ for incident optical wavelengths of $1.55,1.47$, and $1.31 \mu \mathrm{m}$, respectively.

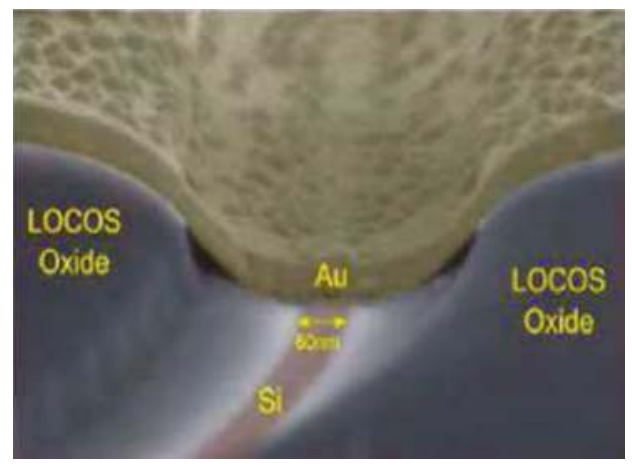

Fig. 16. SEM micrograph of the nanoscale Schottky contact proposed in (Goykhman et al., 2011). Reprinted with permission from I. Goykhmanet al., "Locally Oxidized Silicon SurfacePlasmon Schottky Detector for Telecom Regime," Nano Lett. 11, 2219-2224. Copyright 2011 american Chemical Society.

\section{Conclusion}

In this chapter an overview on the NIR all-Si photodetectors based on the IPE has been presented. First, we have attempted to elucidate the IPE effects allowing Si absorption at sub band-gap wavelengths and the main figures of merit of IPE-based devices. Then, a quantitative comparison of the photodetectors proposed in the scientific literature, including both bulk and integrated devices, have been reviewed. Unfortunately, the efficiency of devices is low compared to that of detectors based on inter-band absorption. This property is a direct result of many factors: 1) the low absorption due to high reflectivity of the metal layer at NIR wavelengths, 2) the conservation of momentum during carrier emission over the potential barrier which lowers the carriers emission probability into semiconductor, 3 ) the excitation of carriers lying in states far below the Fermi energy, which get very low probability to overcome the Schottky barrier. While the first and second points can be partially improved by using an optical cavity and a thin metal film, respectively, the third point remains the main limiting factor of IPE. In 1971 Sheperd, Vickers and Yang (Sheperd et al., 1971) recommended replacing the metal electrodes IPE-based photodiodes with degenerate semiconductors. They reasoned that reducing the Fermi energy of electrode by substitution of a degenerate semiconductor could improve emission efficiency as much as 20 -fold. Even if NIR IPE-based devices efficiency is still only adapted for power monitoring application, in our opinion that new structures based on the aforementioned insights could play a key role in telecommunication field and could open new frontiers in the field of lowcost silicon photonic.

\section{References}

Akbari A. \& Berini, P. (2009). Schottky contact surface-plasmon detector integrated with an asymmetric metal stripe waveguide. Appl. Phys. Lett., Vol.95, No.2, pp. 021104. 
Akbari, A.; Tait, R. N. \& Berini, P. (2010). Surface plasmon waveguide Schottky detector. Opt. Express, Vol.18, No.8, pp. 8505- 8514.

Archer, R.J. \& Cohen, J. (1973). Schottky-Barrier Monolithic Detector Having Ultrathin Metal Layer. U.S. Patent 3,757,123

Barnes, W. L.; Dereux, A. \& Ebbesen, T.W. (2003) Surface plasmon subwavelength optics. Nature, Vol.424, No.6950, pp. 824-830

Boyle, W.S. \& Smith, G.E. (1970). Charge-coupled semiconductor devices. Bell Syst. Tech. J., Vol.49, pp. 587-593

Bradley, J.D.B.; Jessop, P.E. \& Knights, A.P. (2005). Silicon waveguide-integrated optical power monitor with enhanced sensitivity at $1550 \mathrm{~nm}$. Appl. Phys. Lett., Vol. 86, No.24, pp. 241103.

Capone, B.R.; Skolnik, L.H.; Taylor, R.W.; Shepherd, F.D.; Roosild, S.A.; Ewing, W.; Kosonocky, W.F. \& Kohn, E.S. (1978). Evaluation of Schottky IRCCD Staring Mosaic Focal Plane. 22nd Int. Tech. Symp. Society of Photo-Optical Instrumentation Engineers (SPIE), San Diego, Aug. 28-29

Casalino, M. ; Sirleto, L. ; Moretti, L. ; Della Corte, F. \& Rendina, I. (2006a). Design of a silicon RCE schottky photodetector working at 1.55 micron. Journal of luminescence, Vol.121, pp. 399-402.

Casalino, M. ; Sirleto, L. ; Moretti, L. ; Della Corte, F. \& Rendina, I. (2006b). Design of a silicon resonant cavity enhanced photodetector based on the internal photoemission effect at $1.55 \mu \mathrm{m}$. Journal of Optics A: Pure and applied optics, Vol.8, pp. 909-913.

Casalino, M.; Sirleto, L.; Moretti, L.; Gioffrè, M.; Coppola, G. \& Rendina, I. (2008a). Silicon resonant cavity enhanced photodetector based on the internal photoemission effect at $1.55 \mu \mathrm{m}$ : Fabrication and characterization. Appl. Phys. Lett., Vol.92, No.25, pp. 251104

Casalino, M.; Sirleto, L.; Moretti, L. \& Rendina, I. (2008b). A silicon compatible resonant cavity enhanced photodetector working at $1.55 \mu \mathrm{m}$. Semicond. Sci. Technol., Vol.23, No.7, pp. 075001

Casalino, M. ; Coppola, G. ; Iodice, M. ; Rendina, I. \& Sirleto, L. (2010a). Near Infrared AllSilicon Photodetectors: State of the Art and Perspectives. Sensors, Vol.10, No.12, pp. 10571-10600

Casalino, M.; Coppola, G.; Gioffrè, M.; Iodice, M.; Moretti, L.; Rendina, I. \& Sirleto, L. (2010b). Cavity enhanced internal photoemission effect in silicon photodiode for sub-bandgap detection. J. Lightw. Technol., Vol. 28, No.22, pp. 3266-3272

Casalino, M.; Sirleto, L.; Iodice, M.; Saffioti, N.; Gioffrè, M.; Rendina, I \& Coppola, G. (2010c). Cu/p-Si Schottky barrier-based near infrared photodetector integrated with a silicon-on-insulator waveguide. Appl. Phys. Lett., Vol.96, No.24, pp. 241112.

Chan, E.Y; Card, H.C. \& Teich, M.C. (1980a). Internal Photoemission Mechanism at interfaces between Germanium and Thin Metal Films. IEEE Journal of Quantum Electronics, Vol.QE-16, No.3, pp. 373-381

Chan, E.Y. \& Card, H.C. (1980b). Near IR interband transitions and optical parameters of metal-germanium contacts. Applied Optics, Vol.19, No.8, pp. 1309

Donati, S. (1999). Photodetectors: Devices, circuits, and applications. Prentice Hall PTR, New Jersey, USA 
Ebbesen, W. ; Lezec, H.J. ; Ghaemi, H.F. ; Thio, T. \& Wolff, P.A. (1997). Extraordinary optical transmission through sub-wavelength hole arrays. Nature, Vol.391, pp 667-669

Elabd, H. \& Kosonocky, W.F. (1982). Theory and measurements of photoresponse for thin film $\mathrm{Pd}_{2} \mathrm{Si}$ and $\mathrm{PtSi}$ infrared Schottky-barrier detectors with optical cavity. RCA Review, Vol. 43, pp. 569-589

Elabd, H.; Villani, T. \& Kosonocky, W.F. (1982). Palladium-Silicide Schottky-Barrier IR-CCD for SWIR Applications at Intermediate Temperatures. IEEE Trans. Electron Devices Lett., Vol. EDL-3, pp. 89-90

Fowler, R.H. (1931). The Analysis of Photoelectric Sensitivity Curves for Clean Metals at Various Temperatures. Physical Review, Vol. 38, pp. 45-56

Goykhman, I.; Desiatov, B.; Khurgin, J.; Shappir, J. \& Levy U. (2011). Locally Oxidized Silicon Surface-Plasmon Schottky Detector for Telecom Regime. Nano Lett. Vol. 11, pp. 2219-2224.

Inoue, M.; Seto, T.; Takahashi, S.; Itoh, S.; Yagi, H.; Siraishi, T.; Endo, K. \& Kimata, M. (1997). Portable high performance camera with 801x512 PtSi-SB IRCSD, SPIE Proc., Vol.3061, pp. 150-158

Jalali, B \& Fathpour, S. (2006). Silicon Photonics. J. Lightwave Technol., Vol.24, No.12, pp. 4600-4615

Kimata, M.; Yutani, N.; Tsubouchi, N. \& Seto, T. (1992). High performance 1040x1040 element PtSi Schottky-barrier image sensor. SPIE Proc., Vol.1762, pp. 350-360

Kimata, M. \& Tsubouchi, N. (1995). Schottky barrier photoemissive detectors. In: Infrared Photon Detectors, A. Rogalski (Ed.), pp. 299-349, SPIE Optical Engineering Press, Bellingham

Kimata, M.; Ozeki, T.; Nunoshita, M. \& Ito, S. (1997). PtSi Schottky-barrier infrared FPAs with CSD readout. SPIE Proc., Vol.3179, pp. 212-223

Kimata, M.; Ueno, M.; Yagi, H.; Shiraishi, T.; Kawai, M.; Endo, K.; Kosasayama, Y.; Sone, T.; Ozeki, T. \& Tsubouchi, N. (1998). PtSi Schottky-barrier infrared focal plane arrays, Opto-Electronics Review, Vol.6, pp. 1-10

Kimata, M. (2000). Metal silicide Schottky infrared detector arrays. In: Infrared Detectors and Emitters: Materials and Devices, Kluwer Academic Publishers, Boston, USA

Kimerling, L.C.; Dal Negro, L.; Saini, S.; Yi, Y.; Ahn, D.; Akiyama, S.; Cannon, D.; Liu, J.; Sandland, J.G.; Sparacin, D.; Michel, J.; Wada, K. \& Watts, M.R. (2004). Silicon Photonics: Topics in Applied Physics, Springer, ISBN 3-642-05909-0, Berlin, Germania

Kohn, E.S.; Roosild, S.A.; Shepherd, F.D. \& Yang, A.C. (1975). Infrared Imaging with Monolithic CDD-Addressed Schottky-Barrier Detector Arrays, Theoretical and Experimental Results. Int. Conf. on Application on CCD's, San Diego, Oct. 29-31

Kosonocky, W.F.; Kohn, E.S.; Shalleross, F.V.; Sauer, D.J.; Shepherd, F.D.; Skolnik, L.H.; Taylor, R.W.; Capone, B.R. \& Roosild, S.A. (1978). Platinum Silicide Schottky-Barrier IR-CCD Image Sensors. Int. Conf. on Application on CCD's, San Diego, Oct. 25-27

Kosonocky, W.F.; Erhardt, H.G.; Meray, G.M.; Shallcross, F.V.; Elabd, H.A.; Cantella, M.; Klein, J.; Skolnik, L.H.; Capone, B.R.; Taylor, R.W.; Ewing, W.; Shepherd, F.D. \& Roosild, S.A. (1980). Advances in Platinum-Silicide Schottky-Barrier IR-CCD Image Sensors. SPIE Proc., Vol. 225, pp. 69-71

Kosonocky, W.F. ; Shallcross, F.V. \& Villani, T.S. (1985). 160x244 Element PtSi SchottkyBarrier IR-CCD Image Sensor. IEEE Trans. Electron Dev., vol. ED-32, No.8, pp. 1564 
Kosonocky, W.F. (1991). Review of infrared image sensors with Schottky-barrier detectors. Optoelectronics Devices and Technologies, Vol.6, pp. 173-203

Kosonocky, W.F. (1992). State-of-the-art in Schottky-barrier IR image sensors. SPIE Proc., Vol.1682, pp. 2-19

Kurianski, J.M.; Shanahan, S.T.; Theden, U.; Green, M.A. \& Storey, J.W.V. (1989). Optimization of the cavity for silicide Schottky infrared detectors. Solid-State Electronics, Vol.32, pp. 97-101

Lee, M. K.; Chu, C. H.; Wang \& Y. H. (2001) 1.55- $\mu \mathrm{m}$ and infrared-band photoresponsivity of a Schottky barrier porous silicon photodetector. Opt. Lett., Vol.26, No.3, pp. 160-162

Liang, T.K.; Tsang, H.K.; Day, I.E.; Drake, J.; Knights, A.P. \& Asghari, M. (2002). Silicon waveguide two-photon absorption detector at $1.5 \mu \mathrm{m}$ wavelength for autocorrelation measurements. Appl. Phys. Lett., Vol.81, No.7, pp. 1323

Liu, A.; Jones, R.; Cohen, O.; Hak, D. \& Paniccia M. (2006). Optical amplification and lasing by stimulated Raman scattering in silicon waveguides. J. Lightw. Technol., Vol.24, No.3, pp. 1440-1445

Liu, A.; Liao, L.; Rubin, D.; Nguyen, H.; Ciftcioglu, B.; Chetrit, Y.; Izhaky, N. \& Paniccia, M. (2007). High-speed optical modulation based on carrier depletion in a silicon waveguide. Opt. Express, Vol.15, No. 2, pp. 660-668

Maier A. (2006). Plasmonics: Fundamentals and Applications. Springer, New York, USA

Michael, C.P.; Borselli, M.; Johnson, T.J.; Chrystal, C. \& Painter, O. (2007). An optical fibertaper probe for wafer-scale microphotonic device characterization. Opt. Express, Vol.15, No. 8, pp. 4745-4752

Muriel, M.A . \& Carballar, A. (1997). Internal field distributions in fiber Bragg gratings. IEEE Photonics technology letters, Vol. 9, No.7, pp. 955, 1997

Olivieri, A.; Akbari A. \& Berini, P. (2010) Surface plasmon waveguide Schottky detectors operating near breakdown. Phys. Status Solidi RRL. Vol 4, No.10, pp. 283 - 285

Reather, H. (1988). Surface Plasmons on Smooth and Rough Surfaces and on Gratings. Springer, Berlin, Germany

Rogalski, A. (1999). Assessment of HgCdTe photodiodes and quantum well infrared photoconductors for long wavelength focal plane arrays. Infrared Phys. Technol., Vol.40, pp. 279-294

Rowe, L.K.; Elsey, M. ; Tarr, N.G. ; Knights, A.P. \& Post, E. (2007). CMOS-compatible optical rib waveguides defined by local oxidation of silicon. Electron. Lett., Vol.43, No.6, pp. 392-393

Scales, C. \& Berini, P. (2004). Schottky Barrier Photodetectors, U.S. Patent No. 7,026,701.

Scales, C.; Breukelaar, I. \& Berini, P. (2009). Surface-plasmon Schottky contact detector based on a symmetric metal stripe in silicon. Opt. Lett., Vol. 35, No.4, pp. 529-531

Scales, C. \& Berini, P. (2010). Thin-film Schottky barrier Photodetector Models. IEEE Journal of Quantum Electronics, Vol.46, No.5, pp. 633-643

Scales, C.; Breukelaar, I.; Charbonneau, R. \& Berini, P. (2011). Infrared Performance of Symmetric Surface-Plasmon Waveguide Schottky Detectors in Si. IEEE J. Lightw. Tech., Vol 29, No. 12, pp. 1852-1860

Sheperd, F.D.; Vickers, V.E. \& Yang, A.C. (1971). Schottky Barrier Photodiode with a Degenerate Semiconductor Active Region. U.S. Patent No. 3.603.847

Shepherd, F.D. \& Yang, A.C. (1973). Silicon Schottky Retinas for Infrared Imaging. IEDM Tech. Dig., pp. 310-313 
Shepherd, F.D.; Taylor, R.W.; Skolnik, L.H.; Capone, B.R.; Roosild, S.A.; Kosonocky, W.F. \& Kohn, E.S. (1979). Schottky IRCCD Thermal Imaging. Adv. Electron. Electron Phys., $7^{\text {th }}$ Symp. Photo-Electronic Image Devices, Vol. 22, pp. 495-512

Shepherd, F.D. (1984). Schottky diode based infrared sensors. SPIE Proc., Vol. 443, pp. 42-49

Shepherd, F.D. (1988). Silicide infrared staring sensors. SPIE Proc., Vol.930, pp. 2-10

Shepherd, F.D. (1998). Platinum silicide internal emission infrared imaging arrays. Academic Press, New York, USA

Shiraishi, T.; Yagi, H.; Endo, K.; Kimata, M.; Ozeki, T.; Kama, K. \& Seto, T. (1996). PtSi FPA with improved CSD operation. SPIE Proc., Vol.2744, pp. 33-43

Sze, S.M. (1981). Physics of Semiconductor Devices. John Wiley \& Sons, New York, USA

Taylor, R.W.; Skolnik, L.H.; Capone, B.R.; Ewing, W.; Shepherd, F.D.; Roosild, S.A.; Cochrum, B.; Cantella, M.; Klein, J.; Kosonocky, W.F. (1980). Improved Platinum Silicide IRCCD Focal Plane. SPIE Proc., Vol. 217, pp. 103-110

Vickers, V.E. (1971). Model of Schottky Barrier Hot-electron-Mode Photodetection. Applied Optics, Vol. 10, No.9, pp. 219

Vivien, L.; Pascal, D.; Lardenois, S.; Marris-Morini, D.; Cassan, E.; Grillot, F.; Laval, S.; Fedeli, J.M. \& El Melhaoui, L. (2006). Light injection in SOI microwaveguides using high-efficiency grating couplers. J. Lightw. Technol., Vol.24, No.10, pp. 3810-3815

Xu, Q.; Manipatruni, S.; Schmidt, B.; Shakya, J. \& Lipson, M. (2007). 12.5 Gbit/s carrier-injectionbased silicon micro-ring silicon modulators. Opt. Express, Vol.15, No. 2,pp. 430-436

Yagi, H.; Yutani, N.; Nakanishi, J.; Kimata, M. \& Nunoshita, M. (1994). A monolithic Schottky-barrier infrared image sensor with $71 \%$ fill factor. Optical Engineering, Vol.33, pp. 1454-1460

Yeh, P. (1988). Optical Waves in Layerer Media. Wiley Interscience Publication, New York, USA

Yuan, H.X. \& Perera, G.U. (1995). Dark current analysis of Si homojunction interfacial work function internal photoemission far-infrared detectors. Appl. Phys. Lett., Vol.66, No.17, pp. 2262-2264

Zhu, S.; Yu, M.B.; Lo, G.Q. \& Kwong, D.L. (2008a). Near-infrared waveguide-based nickel silicide Schottky-barrier photodetector for optical communications. Appl. Phys. Lett., Vol.92, No.8, pp. 081103

Zhu, S.; Lo, G.Q. \& Kwong, L. (2008b). Low-cost and high-gain silicide Schottky-barrier collector phototransistor integrated on Si waveguide for infrared detection. Appl. Phys. Lett., Vol. 93, No.7, pp. 071108

Zhu, S.; Lo, G.Q. \& Kwong, D.L. (2008c) Low-Cost and High-Speed SOI Waveguide-Based Silicide Schottky-Barrier MSM Photodetectors for Broadband Optical Communications. IEEE Phot. Tech. Lett., Vol. 20, No.16, pp. 1396-1398 


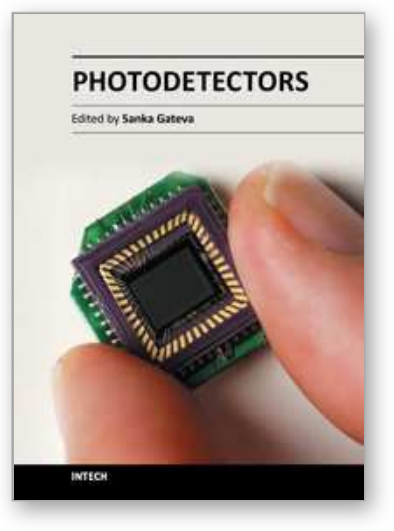

\author{
Photodetectors \\ Edited by Dr. Sanka Gateva
}

ISBN 978-953-51-0358-5

Hard cover, 460 pages

Publisher InTech

Published online 23, March, 2012

Published in print edition March, 2012

In this book some recent advances in development of photodetectors and photodetection systems for specific applications are included. In the first section of the book nine different types of photodetectors and their characteristics are presented. Next, some theoretical aspects and simulations are discussed. The last eight chapters are devoted to the development of photodetection systems for imaging, particle size analysis, transfers of time, measurement of vibrations, magnetic field, polarization of light, and particle energy. The book is addressed to students, engineers, and researchers working in the field of photonics and advanced technologies.

\title{
How to reference
}

In order to correctly reference this scholarly work, feel free to copy and paste the following:

Maurizio Casalino, Luigi Sirleto, Mario Iodice and Giuseppe Coppola (2012). Silicon Photodetectors Based on Internal Photoemission Effect: The Challenge of Detecting Near-Infrared Light, Photodetectors, Dr. Sanka Gateva (Ed.), ISBN: 978-953-51-0358-5, InTech, Available from:

http://www.intechopen.com/books/photodetectors/silicon-photodetectors-the-challenge-of-detecting-nearinfrared-light

\section{INTECH}

open science | open minds

\section{InTech Europe}

University Campus STeP Ri Slavka Krautzeka 83/A 51000 Rijeka, Croatia Phone: +385 (51) 770447 Fax: +385 (51) 686166 www.intechopen.com

\section{InTech China}

Unit 405, Office Block, Hotel Equatorial Shanghai No.65, Yan An Road (West), Shanghai, 200040, China 中国上海市延安西路65号上海国际贵都大饭店办公楼 405 单元 Phone: +86-21-62489820

Fax: +86-21-62489821 
(C) 2012 The Author(s). Licensee IntechOpen. This is an open access article distributed under the terms of the Creative Commons Attribution 3.0 License, which permits unrestricted use, distribution, and reproduction in any medium, provided the original work is properly cited. 